Check for updates

Cite this: Mater. Adv., 2021

2. 1731

Received 22nd November 2020,

Accepted 1st February 2021

DOI: 10.1039/d0ma00911c

rsc.li/materials-advances

\section{Intensifying sustainable solar water production by steam heat internal circulation $\dagger$}

\author{
Zhenzhen Guo, You Xu, Zihe Chen, Fang Yu, Jiacheng Yin, Tao Mei $\mathbb{D}$ and \\ Xianbao Wang (D) *
}

\begin{abstract}
Solar interfacial evaporation, as a green technology, is currently one of the feasible means for producing potable water for practical applications. However, the sustainable development of this technology faces great challenges due to the low conversion efficiency of solar to steam energy and, especially, the limited capabilities for the storage and reuse of steam energy. Herein, a simple steam heat internal circulation system was designed for integrated steam condensation, heat storage, and circulation, to achieve maximum solar energy utilization. Low-cost, easy-to-prepare, non-polluting carbon-blackloaded glass fiber cotton (CBGF) was selected as an interfacial evaporator, which can enable continuous evaporation for $42 \mathrm{~h}$ in highly concentrated brine (20 wt\%) with excellent photothermal stability and near $100 \%$ ion rejection. In the simple system, the steam energy is stored as electricity by thermoelectric (TE) devices, and it can be further used to enhance water evaporation. In such a circulating system, the water production rates can increase 1.32- and 1.44-fold compared with those of a system without TE devices under 1 and 2 sun illumination, respectively. The steam heat internal circulation achieves enhanced water yields and shows great potential to deal with freshwater shortages.
\end{abstract}

\section{Introduction}

Solar energy is a clean, pollution-free and abundant energy source. Common utilization methods include light to electricity conversion, ${ }^{1,2}$ as performed by solar cells, and light to heat conversion, ${ }^{3-5}$ as achieved by solar water evaporation technology (SWET). SWET has attracted widespread attention due to its high efficiency for green energy harvesting (>90\%) and practical application for dealing with freshwater shortages. There are three basic stages for SWET: bottom heating evaporation, fluid heating evaporation, and solar interface evaporation. ${ }^{6}$ At present, the interface evaporation technology is the focus of research, giving higher solar evaporation rates than bottom heating and fluid heating evaporation. It has been extensively studied in the fields of seawater desalination, sterilization, sewage treatment, etc. ${ }^{7-11}$

The interfacial evaporators display strong solar energy acquisition, orderly water supply, and efficient heat arrangement. ${ }^{12-17}$ The problems of high-rate evaporation and salt treatment have been solved in multiple ways through the selection of photothermal materials or systems, and the clever

Key Laboratory for the Green Preparation and Application of Functional Materials, Ministry of Education, Hubei Key Laboratory of Polymer Materials, School of Materials Science and Engineering, Hubei University, Wuhan 430062, China. E-mail:wxb@hubu.edu.cn

$\dagger$ Electronic supplementary information (ESI) available. See DOI: 10.1039/ d0ma00911c design of macrostructures. ${ }^{18-25}$ However, the storage of waste heat is truly advantageous for practical applications and the sustainable development of this solar-driven evaporation technology. ${ }^{26}$ Currently, storing heat as electricity has become a common approach. Heat storage is manifested in integrated water evaporation and electric accumulation (Table S1, ESI $\dagger$ ), ${ }^{27-31}$ but this is limited to the use of the heat on the surface of the photothermal materials, and it would affect the interface evaporation technology if it were to play a major role. Exceptionally, Zhu's group once designed a thermoelectric (TE) device to store steam heat as electricity, but the placement of the TE device affected the direct sunlight reaching the photothermal materials. ${ }^{32}$ Zheng's group used the biological material bamboo as an evaporator and used its waste heat to generate electricity, and a $90.7 \mathrm{mV}$ voltage could be achieved under 1 sun. ${ }^{33}$ However, such research on the storage of waste heat raises the important question of how to reasonably use this stored energy for the sustainable development of interfacial evaporation, thus realizing the reuse of waste heat.

In this work, we focus our study on the reuse of waste heat for sustainable development by a steam heat internal circulation system with integrated steam condensation, heat storage and circulation. A low-cost, easy-to-prepare, pollution-free carbon black-loaded glass fiber cotton (CBGF) was selected as the photothermal material, and under 1 sun, the interfacial evaporation rate reached up to $1.6 \mathrm{~kg} \mathrm{~m}^{-2} \mathrm{~h}^{-1}$. The evaporator could continuously work for $42 \mathrm{~h}$ in a highly concentrated brine (20 wt\%), and offered 
excellent photothermal stability and near $100 \%$ ion rejection. In the system, the electricity from steam heat could reach voltages of 88.27, 156.75 and $210.7 \mathrm{eV}$ under 1 sun, 2 suns and 3 suns, respectively over $1 \mathrm{~h}$ with one TE device. After the series connection of three TE devices, the voltages of $215.26 \mathrm{eV}$ and $407.03 \mathrm{eV}$ could be generated under 1 sun and 2 suns, respectively. The electricity from waste heat was reused to increase the water yield by the transition from electricity back to heat. The water yields could reach 1.32 and 1.44 times those achieved without TE devices under 1 sun and 2 suns, respectively. Such a steam heat internal circulation system not only improves water production, but also maximizes the use of solar energy. The concept of using the waste heat to enhance internal water evaporation offers the prospect of sustainable applications in green water treatment technology.

\section{Experimental section}

\subsection{Materials}

Conductive carbon black (CB) was bought at No. 73, Jianshe South Road, Yingze District, Taiyuan City. Glacial acetic acid $\left(\mathrm{CH}_{3} \mathrm{COOH}\right)$ was obtained from Sinopharm Chemical Reagent Co. Glass fiber cotton (GF; thickness $3 \mathrm{~mm}$ ) was obtained from Yanjin Chemical Building Materials Co., Taobao. A commercial thermoelectric (TE) device (module: SP1848-27145, Size: $4 \times 4 \mathrm{~cm}$, Seebeck coefficient: $0.04-0.048 \mathrm{~V}^{\circ} \mathrm{C}^{-1}$ ) was used as the power generation device to receive and convert heat energy.

\subsection{Fabrication of CBGF}

CB (200 mg) was added to $200 \mathrm{~mL}$ deionized water, then $16 \mathrm{~mL}$ $\mathrm{CH}_{3} \mathrm{COOH}$ was added, and ultrasonic dispersion was performed for $1 \mathrm{~h}$. GF was submerged in the above solution for $50 \mathrm{~min}$, and every $10 \mathrm{~min}$, the GF in the solution was shaken several times to make the load more even. Finally, the CBGF was dried for $24 \mathrm{~h}$ in a drying oven at $60{ }^{\circ} \mathrm{C}$.

\subsection{Characterization of CBGF}

The morphologies of the CBGF and GF were examined by FieldEmission Scanning Electron Microscopy (FE-SEM, JSM7100F). X-ray diffraction (XRD) data for $\mathrm{CB}, \mathrm{GF}$ and $\mathrm{CBGF}$ were obtained using an X-ray diffractometer (Bruker, Germany). The optical performance of CBGF was recorded by ultraviolet-visible-nearinfrared spectrophotometry (UV-VIS-NIR, Shimadze UV-3600 double beam spectrophotometer). A standard PT-705-A contactangle analyzer (Pusite Detection Equipment Co., Dongguan, China) was used to measure the contact angles of the different samples. Inductively coupled plasma-optical emission spectrometry (ICP-OES, EP Optimal 8000) was used to measure the ion concentrations of different water samples.

\subsection{Solar interfacial evaporation}

The evaporators were floated on glass containers containing water which were photothermally tested using a solar simulator (PLS-FX300HU, AM1.5). An optical power meter was used for measurement (CEL-NP2000-2, Beijing Education Au-light Co., Ltd). The weight changes of water over time were recorded using a balance (accuracy of $0.0001 \mathrm{~g}$ ) and a computer. The surface temperature changes over time were measured by thermocouples (OMEGA, INSP\#33306, 5TC-TT-K-30-197) and a hand-held infrared instrument (FLIR E4 Pro, America), and the values were recorded by a data acquisition device (KEYSIGHT, 34972A). During testing, the room temperature was kept at $\sim 25{ }^{\circ} \mathrm{C}$. The outdoor experiment was carried out on the roof of Hubei University (8:00-18:00, September 3, 2020).

\subsection{Steam heat internal circulation system}

The system consists of a photothermal evaporator and thermal storage devices (Fig. 1). The photothermal evaporator contains a spectrally selective solar absorber, ${ }^{34} \mathrm{CBGF}$, and a water channel. The steam overflows at the lower end of the photothermal evaporator, then condenses, and the heat is stored through the TE devices. The voltage is recorded by a data acquisition device (KEYSIGHT, 34972A). The TE devices are connected to the CBGF by a thin copper wire to realize the internal steam heat-electricity-thermal circulation.

\section{Results and discussion}

\subsection{Fabrication and characterization of CBGF}

The CBGF was fabricated through simple immersion (Fig. 2a). CB was ultrasonically dispersed in a mixture of deionized water
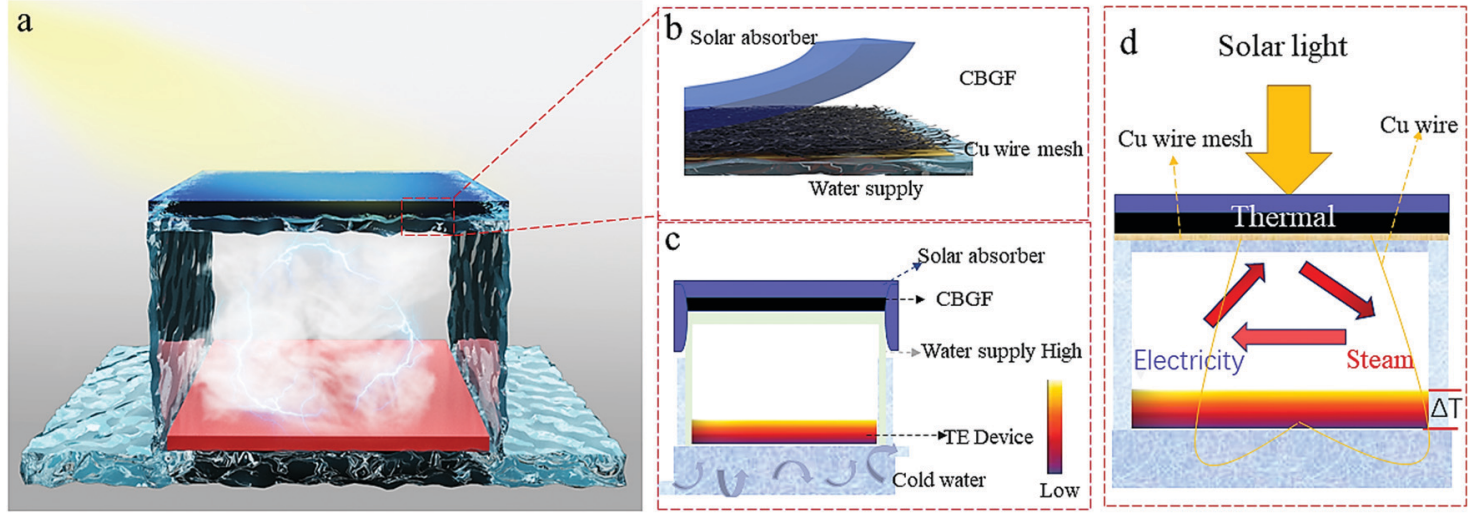

Fig. 1 The structure of the steam heat internal circulation system using a steam heat-electricity-thermal cycle. 




Fig. 2 (a) The preparation process for CBGF. (b and c) SEM images of the GF surfaces. (d) An SEM cross-sectional image of GF. (e-g) SEM images of the CBGF surfaces. (h-i) An SEM cross-sectional image of CBGF. (j) XRD patterns of CB, GF, and CBGF.

and $\mathrm{CH}_{3} \mathrm{COOH}$. After immersing $\mathrm{GF}$ in the above solution for $50 \mathrm{~min}$, it was dried to obtain CBGF. SEM images of the GF and CBGF are displayed in Fig. 2b-i. Fig. $2 b$ and $c$ are surface images of GF, which show that GF is composed of many staggered fibers. Fig. $2 \mathrm{~d}$ is a cross-sectional view of GF showing rows of fibers. The diameters of the fibers are about 4-10 um and the surfaces of these fibers are very smooth. After loading the GF with $\mathrm{CB}$, it can be seen from the surface images (Fig. 2e and f) and cross-sectional images (Fig. 2h-i) of CBGF that the surfaces of these fibers are rough and are loaded with nanosized particles (Fig. 2g). Fig. 2j shows the XRD patterns of CB, GF and CBGF. CB displays two peaks at $2 \theta=25.0^{\circ}$ and $43.3^{\circ}$, which are due to the (002) and (101) graphitic planes, respectively. GF only has one peak at $\sim 25.0^{\circ}$ corresponding to the (002) plane. CBGF shows a peak at $2 \theta=25.0^{\circ}$ and a weak peak at $2 \theta=43.0^{\circ}$, implying that the CB was successfully loaded onto the GF.

The water supply performance was detected through water contact angle tests (Fig. 3a). The dry GF (Fig. $3 \mathrm{a}_{1}$ ) and CBGF (Fig. $3 \mathrm{a}_{2}$ ) display hydrophobic properties; the contact angles of the water droplets are $134.6^{\circ}$ and $130.8^{\circ}$, respectively. However, the wet CBGF (Fig. $3 \mathrm{a}_{3}$ and $\mathrm{a}_{4}$ ) shows a superior hygroscopicity, and the water droplet is absorbed within $20 \mathrm{~ms}$, indicating that the evaporator has an excellent water supply performance. The capacity of optical absorption for CBGF was evaluated by UV-Vis-NIR absorption. As shown in Fig. 3b and Fig. S1 (ESI†), the absorption of dry CBGF is approximately $85.0 \%$, while in the wavelength range of $300-2000 \mathrm{~nm}$, the absorption of wet CBGF can reach above $90 \%$. The wavelength range corresponds to the main emission spectrum of the sun, suggesting that the CBGF has a good light absorption throughout the solar spectrum. The surface temperature of the evaporation system using CBGF rapidly increases and can reach $36.6{ }^{\circ} \mathrm{C}$ while wet, under 1 sun illumination (Fig. 3c and d). The top surface of CBGF is a hot local area, which greatly reduces the heat loss of the system.

\subsection{Interfacial evaporation performance of CBGF}

Indoor solar evaporation experiments were used to accurately investigate the interfacial evaporation performance of CBGF (Fig. 4a). The evaporator floats on the water (Fig. S2, ESI $\dagger$ ), and a light density of $1 \mathrm{~kW} \mathrm{~m}^{-2}$ (1 sun) is provided by a simulated sunlight source. The interfacial evaporation rate recorded by an electronic balance is shown on a computer. From the moment that the light source is turned on, the weight of the system 

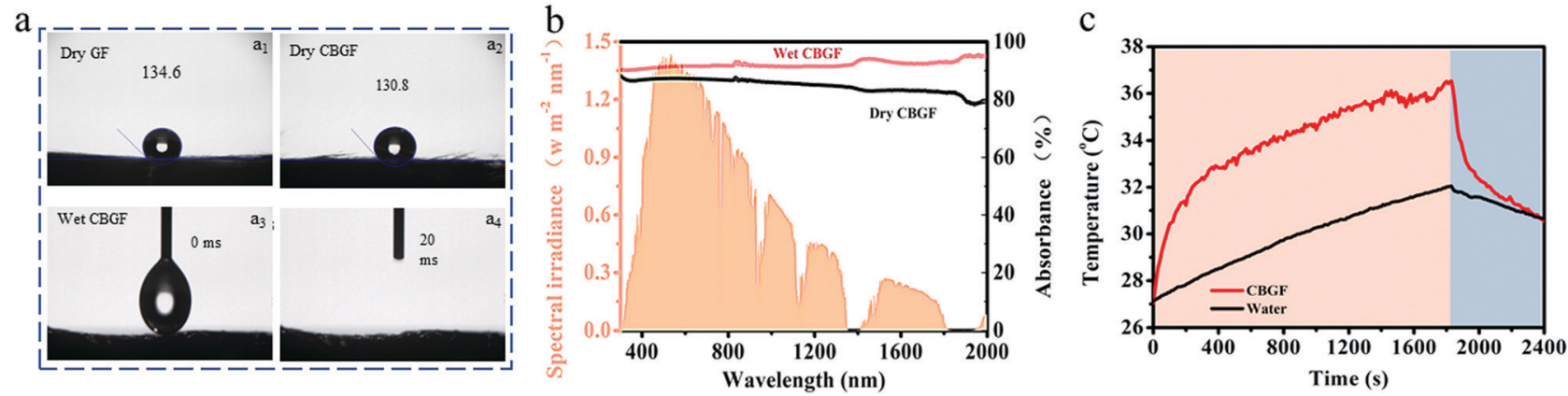

d



Fig. 3 (a) Contact angle tests of dry GF, dry CBGF, and wet CBGF. (b) Light absorbance by wet CBGF and dry CBGF. (c and d) Surface temperatures and infrared images of CBGF when illuminated with 1 sun.

decreases gradually over time due to the escape of water vapor into the environment. The photothermal evaporation performances of CBGF prepared with different soaking times (10, 30, 50, 70 and $100 \mathrm{~min}$ ) are shown in Fig. S3 (ESI $\dagger$ ). After half an hour of evaporation, the weight changes for the systems prepared with different CBGF soaking times are $0.644 \mathrm{~kg} \mathrm{~m}^{-2}$ for $10 \mathrm{~min}, 0.664 \mathrm{~kg} \mathrm{~m}^{-2}$ for $30 \mathrm{~min}, 0.703 \mathrm{~kg} \mathrm{~m}^{-2}$ for $50 \mathrm{~min}$, $0.710 \mathrm{~kg} \mathrm{~m}^{-2}$ for $70 \mathrm{~min}$ and $0.719 \mathrm{~kg} \mathrm{~m}^{-2}$ for $100 \mathrm{~min}$. The results show that a 50 min soaking time is the best for the preparation of CBGF. The water weight changes of systems comprising water only, GF and CBGF were further tested. As shown in Fig. $4 \mathrm{~b}$, the steam generated from each sample increases steadily over time. It is clear that CBGF has a higher interfacial evaporation performance giving more water evaporation than the water-only and GF systems. The stable evaporation rate of CBGF can reach $1.6 \mathrm{~kg} \mathrm{~m}^{-2} \mathrm{~h}^{-1}$, which is 6.15 times that of water only, and 3.26 times that of GF (Fig. 4c). The evaporation performances of CBGF in highly concentrated salt water, acid solution and alkali solution (Fig. S4, ESI $\dagger$ ) were also assessed. As shown in Fig. 4d, in a $20 \mathrm{wt} \% \mathrm{NaCl}$ solution, the weight change is lower than that in pure water. However, during a $2 \mathrm{~h}$ photothermal test, the evaporation rate in highly concentrated salt water can still be maintained at $1.41 \mathrm{~kg} \mathrm{~m}^{-2} \mathrm{~h}^{-1}$ (Fig. S5, ESI $\dagger$ ).

The stability of CBGF was tested through a long-term photothermal test (Fig. 4e and Fig. S6, ESI †). After 7 consecutive days of photothermal testing for $6 \mathrm{~h}$ a day, the CBGF can still maintain an evaporation rate higher than $1.28 \mathrm{~kg} \mathrm{~m}^{-2} \mathrm{~h}^{-1}$ in the high-concentration brine. In each 1 day test, the evaporation rate of CBGF drops slightly, but, on the following day, the trend in evaporation rate for CBGF is consistent with that obtained on the previous day. The main reason may be that the salt accumulated under light is re-dissolved into the water in the dark. The result of the long-term test demonstrates that CBGF has good photothermal evaporation stability. An outdoor experiment was performed on the roof of the School of Materials Science and Engineering, Hubei University (8:00-18:00, September 3,2020$)$. The solar intensity was $43-940 \mathrm{~kW} \mathrm{~m}^{-2}$ from $8: 00$ to $18: 00$ and the temperature during the day was $25-34{ }^{\circ} \mathrm{C}$ (Fig. S7, ESI $\dagger$ ). During the test, the ground heat reached the very high temperature of $55.1{ }^{\circ} \mathrm{C}$ at $13: 00$. Since geothermal heat can heat water to promote water evaporation, an evaporation rate of up to $1.9 \mathrm{~kg} \mathrm{~m}^{-2} \mathrm{~h}^{-1}$ could be achieved. The results of seawater remediation before and after desalination with CBGF are shown in Fig. 4f. The concentrations of $\mathrm{Na}^{+}, \mathrm{Mg}^{2+}, \mathrm{K}^{+}$, and $\mathrm{Ca}^{2+}$ in seawater decrease to $0.6,0.017,0.4$ and $0.29 \mathrm{mg} \mathrm{L}^{-1}$, which are below the drinking standards of the World Health Organization. In addition, the treatment of sewage containing heavy metal ions is shown in Fig. 4g. CBGF shows high-efficiency purification ability. The ion concentrations of $\mathrm{Co}^{2+}, \mathrm{Mn}^{2+}, \mathrm{Cu}^{2+}$, and $\mathrm{Zn}^{2+}$ decrease to $0.0056,0.0126,0.026$ and $0.053 \mathrm{mg} \mathrm{L}^{-1}$ indicating an ultra-high rejection of more than $99.999 \%$.

It is notable that CBGF is prepared in a low cost, simple process, and shows acid and alkali resistance (Fig. S4, ESI $\dagger$ ) and high temperature resistance (Fig. S8, ESI $\dagger$ ), so it has good prospects for practical applications.

\subsection{Steam heat internal circulation system for heat storage and circulation}

This circulation system is composed of five parts: a solar absorber, CBGF, a water channel, a TE device, and a water circulation platform (Fig. 5a and Fig. S9, ESI $\dagger$ ). The solar 

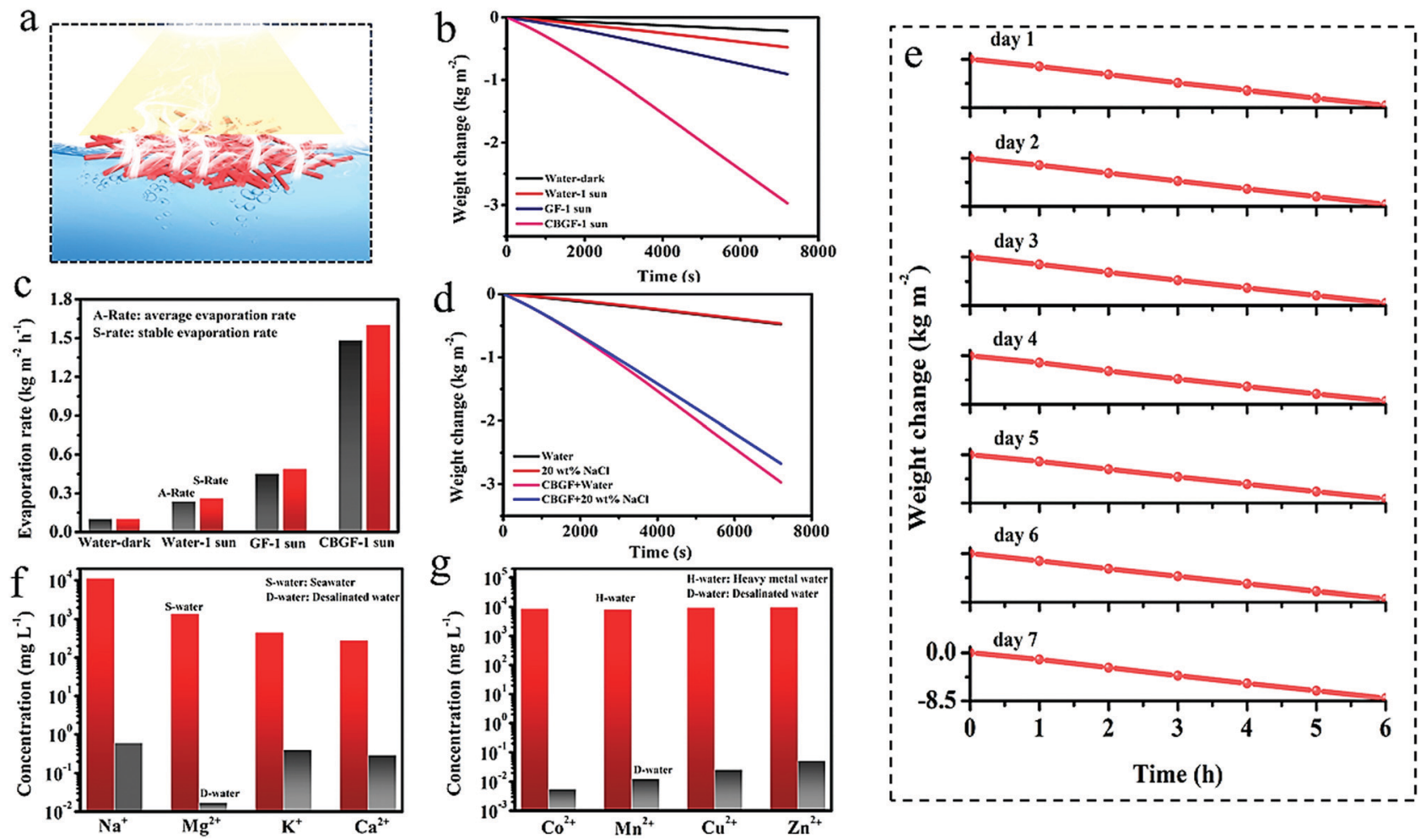

Fig. 4 (a) A schematic diagram of the use of CBGF for solar interfacial evaporation. (b) Time-dependent weight changes of systems based on water only, GF, and CBGF under 1 sun. (c) Evaporation rates calculated for the water, GF, and CBGF systems under 1 sun. (d) An evaporation performance comparison of CBGF in pure water and salt water under 1 sun. (e) The long-term photothermal testing of CBGF in high-concentration brine. (f) lon concentrations of $\mathrm{Na}^{+}, \mathrm{K}^{+}, \mathrm{Ca}^{2+}$, and $\mathrm{Mg}^{2+}$ in seawater and desalinated water. $(\mathrm{g})$ lon concentrations of $\mathrm{Co}^{2+}, \mathrm{Mn}^{2+}, \mathrm{Cu}^{2+}$, and $\mathrm{Zn}^{2+}$ in sewage before and after purification.

absorber makes the produced steam overflow downwards (Fig. S10, ESI $\dagger$ ). This happens mainly because it blocks the other outlets for the steam, forcing it to escape from the lower end of the system and condense at the lower end. This solves the problem seen in traditional steam condensing devices in which solar light absorption is reduced by the condensation of steam on the upper part of the condensing device. Furthermore, it can enhance the surface temperature of CBGF (Fig. S11, ESI $\dagger$ ). After half an hour under 1 sun, the CBGF shows a surface temperature of $36.6{ }^{\circ} \mathrm{C}$. However, when the upper end is covered with a solar absorber, the surface temperature can reach $52{ }^{\circ} \mathrm{C}$. CBGF, as an evaporator, can effectively use solar energy to generate steam. The water channel is two-dimensional (airlaid paper), and can effectively transfer water to the photothermal evaporator. The TE device generates electricity through the temperature difference between the steam heat and the water circulation platform. The temperature of the water circulation platform is maintained at a steady state of about $21-23^{\circ} \mathrm{C}$. The voltage of the TE device was recorded to demonstrate the capability of heat storage. Fig. S12 (ESI $\dagger$ ) shows the voltage with water circulation (WC) and without the water circulation platform. The voltage increases with increasing illumination time, and after $1 \mathrm{~h}$ of light, the voltage of the system with water circulation can reach $88.24 \mathrm{eV}$, while the system without water circulation can only reach $66.6 \mathrm{eV}$. This is mainly because the water circulation ensures the stability of the bottom temperature, creating a greater temperature difference.
In addition, under the same conditions, the voltage in the system without CBGF is only $58.3 \mathrm{eV}$, lower than that of the system with CBGF (Fig. S13, ESI $\dagger$ ), which confirms that CBGF has a positive effect on the entire evaporation system. Fig. $5 \mathrm{~b}$ shows the voltage of the system under different light intensities. The voltage increases with increasing light intensity. Due to higher temperature differences, the voltage can reach $155.76 \mathrm{eV}$ and $212.64 \mathrm{eV}$ under 2 suns and 3 suns, respectively, which are 1.76 and 2.41 times that of the system under 1 sun. The total power of the system was tested by a circuit connection (Fig. S14, ESI $\dagger$ ). When a resistance of $100 \Omega$ is loaded, the total power of the system can reach $67.6 \mathrm{~mW}, 210.9 \mathrm{~mW}$ and $395.0 \mathrm{~mW}$ under 1 sun, 2 suns and 3 suns, respectively. The electricity generation of the system with two TE devices (TE-2) and three TE devices (TE-3) (Fig. 5a) through connection in series was further investigated (Fig. 5c). The series connection increases the thickness and expands the propagation path of the steam, thereby increasing the temperature differences, and the temperature difference of each layer can generate electricity, increasing the output of electric energy. After one hour of exposure under 1 sun, the output voltages of the TE-2 and TE-3 systems can reach $162.89 \mathrm{eV}$ and $215.12 \mathrm{eV}$, respectively (Fig. 5c), which are comparable to the voltages generated by the TE- 1 system under 2 suns and 3 suns. Fig. $5 d$ shows a comparison of the total power obtained by the different systems after $1 \mathrm{~h}$ of light radiation. Although the voltages of the TE-2 and TE- 3 systems under 1 sun are higher than the voltage of 


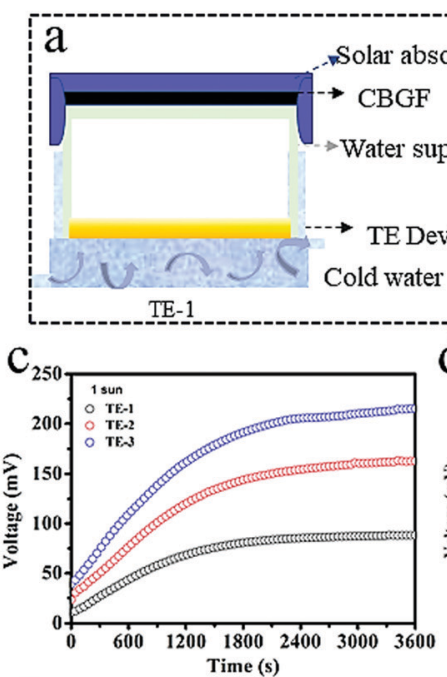

f

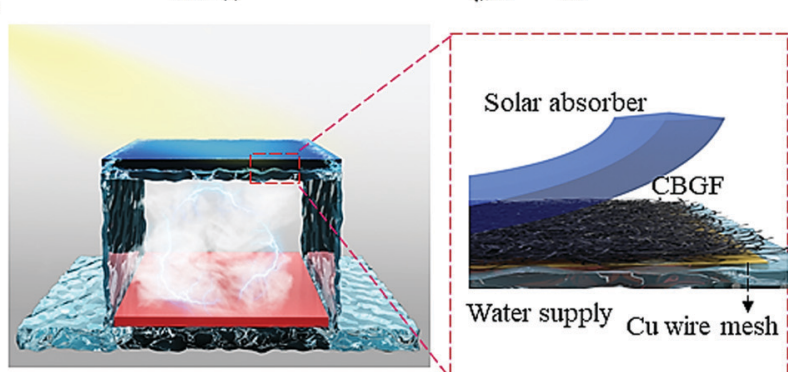

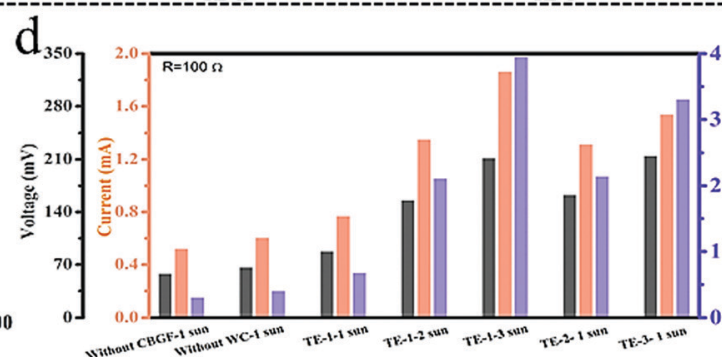

$\mathrm{g}$

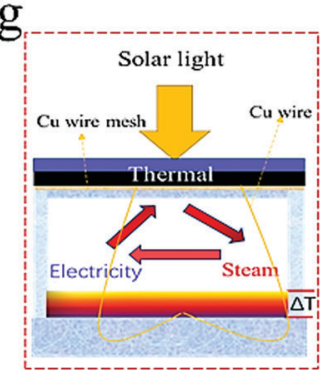

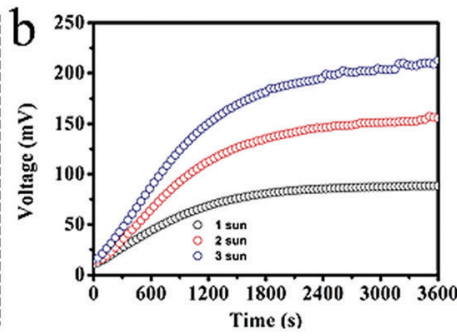

e

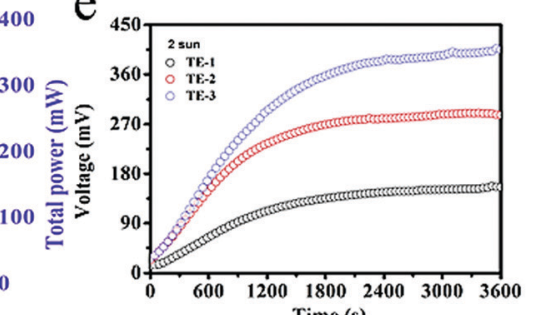

$\mathrm{h}$

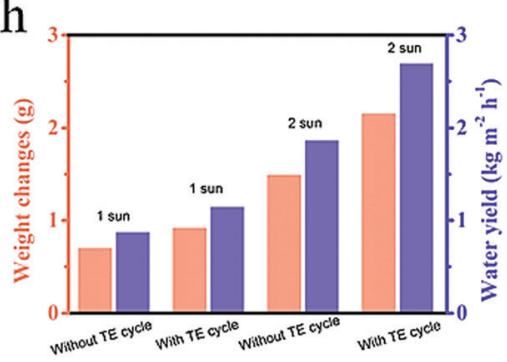

Fig. 5 (a) The structure of thermal-electricity systems (TE-1: one TE device, TE-2: two TE devices, and TE-3: three TE devices). (b) The voltages of the TE-1 system under different light intensities. (c) The voltages of the TE-1, TE-2, and TE-3 systems under 1 sun. (d) A comparison of the total power obtained with different systems after $1 \mathrm{~h}$ of light radiation. (e) The voltages of the TE-1, TE-2, and TE-3 systems under 2 sun illumination. (f and g) The structure of the steam heat internal circulation system. (h) Water yields without the TE cycle and with the TE cycle.

TE- 1 under 2 suns and 3 suns, the total power is less than the total power of TE- 1 under 2 suns and 3 suns, mainly because an increase in the number of TE devices increases the internal resistance. However, it is undeniable that under the same light intensity, the generated voltage and total power will increase with an increase in the number of TE devices. With the same resistance load, the total power of the TE-3 system is 4.88 and 1.54 times as much as that obtained by TE- 1 and TE- 2 under 1 sun, respectively. As the light intensity increases to 2 suns (Fig. 5e), the output voltages of the TE-2 and TE-3 systems can reach $286.77 \mathrm{eV}$ and $405.49 \mathrm{eV}$, respectively. Based on previous research, the voltage can heat the photothermal materials, thereby promoting evaporation (Table S2, ESI $\dagger$ ). ${ }^{35-37}$ Therefore, it is expected that the generated electric energy can be reused to heat the photothermal materials and speed up steam production. In this process, it is possible to increase the voltage output and realize a mutually reinforcing internal circulation system.

Although the interface evaporation rates can reach very high levels in systems previously reported, the yield of clean water collected is not so high. ${ }^{33,38-41}$ There are three reasons for this: (i) In traditional steam collection devices, water vapor generally condenses on the upper part of the device, which causes the water droplets to adhere to the upper surface of the device. These condensed water droplets increase the reflection of light. (ii) The increase of vapor pressure during steam generation in a closed system reduces water evaporation. (iii) There may be incomplete condensation during the condensation process. In our work, in order to solve the problem of light reflection by the water droplets, we chose a device that condenses steam at the bottom of the system. After being exposed to 1 sun and 2 suns for half an hour, $0.697 \mathrm{~g}$ and $1.49 \mathrm{~g}$ clean water can be collected and the condensing rates are $0.87 \mathrm{~kg} \mathrm{~m}^{-2} \mathrm{~h}^{-1}$ and $1.862 \mathrm{~kg} \mathrm{~m}^{-2} \mathrm{~h}^{-1}$, respectively (Fig. 5h). These are still not high condensation rates. Therefore, a steam heat internal circulation system was designed to enhance water production. As shown in Fig. $5 \mathrm{f}$ and $\mathrm{g}$ and Fig. S15 (ESI $\dagger$ ), up to three TE devices were connected to the photothermal material through thin copper wires. The electricity accumulated from the residual heat is reused to heat photothermal materials. After being exposed to 1 sun for half an hour (Fig. $5 \mathrm{~h}$ ), $0.916 \mathrm{~g}$ clean water can be collected; the water yield is $1.15 \mathrm{~kg} \mathrm{~m}^{-2} \mathrm{~h}^{-1}$, which is 1.32 times that obtained without the circulation system. As the light intensity increases to 2 suns, $2.153 \mathrm{~g}$ clean water can be collected in half an hour of irradiation and the condensation rate can reach $2.69 \mathrm{~kg} \mathrm{~m}^{-2} \mathrm{~h}^{-1}$, which is 1.44 times that obtained without the circulation system. The integrated steam heat internal circulation system not only enhances the water yield (Fig. S16, ESI $\dagger$ ), but also requires no additional energy input. With such a low cost and simple process, it is expected to be developed on a large-scale. 


\section{Conclusions}

In conclusion, a new concept is proposed for solar interfacial evaporation in which waste heat is cycled to further enhance water evaporation. Herein, a steam heat internal circulation system was designed and fabricated via introducing CBGF as the evaporator, TE devices for thermal storage, and thermal circulation. CBGF can achieve high interfacial evaporation performance with an evaporation rate of up to $1.6 \mathrm{~kg} \mathrm{~m}^{-2} \mathrm{~h}^{-1}$ under 1 sun, which is comparable to rates reported in previous work. In addition, the simple, pollution-free synthesis technology, low cost, high ion rejection, acid and alkali resistance, and hightemperature resistance provide great advantages for the practical application of this system. In the simple TE-1 system, the electricity from waste heat can reach voltages of 88.27, 156.75, and $210.7 \mathrm{eV}$ under 1 sun, 2 sun and 3 sun illumination, respectively. In the TE-3 system, voltages of $215.26 \mathrm{eV}$ and $407.03 \mathrm{eV}$ can be generated under 1 sun and 2 sun illumination, respectively, due to the higher temperature differences attained. The electricity generated from the waste heat is used to increase the water condensing rate via connecting the TE-3 device to a photothermal material. The water yields can reach 1.32 and 1.44 times those of a system without circulation under 1 sun and 2 sun illumination, respectively.

This work provides a method for maximizing the use of energy, but it still has aspects that can be improved, e.g.: (i) the choice of upper light absorber for maximizing light absorption; (ii) the large-scale series connection of TE devices for generating more electricity; and (iii) the design of the outlet for the condensing water to facilitate faster evaporation and condensation with reduced internal vapor pressure. Overall, the steam heat internal circulation system offers a new strategy for interfacial evaporation technology with enhanced water production and maximum energy reuse.

\section{Author contributions}

Zhenzhen Guo: Main experiment and writing - original draft. You Xu: Methodology. Zihe Chen: Paper mapping. Fang Yu: Writing - editing. Jiacheng Yin: Assistance with data processing. Tao Mei: Basic discussions. Xianbao Wang: Writing reviewing \& editing. All authors contributed to the general discussion.

\section{Conflicts of interest}

The authors declare no conflicts of interest.

\section{Acknowledgements}

This work is financially supported by the National Key R\&D Program of China (Grant 2016YFA0200200) and the Wuhan Science and Technology Bureau of China (2018010401011280).

\section{References}

1 Z. Yang, W. Yang, X. Yang, J. Greer, J. Sheng, B. Yan and J. Ye, Energy Environ. Sci., 2020, 13, 1753-1765.

2 E. W. Diau, ACS Energy Lett., 2017, 2, 334-335.

3 Y. Pang, J. Zhang, R. Ma, Z. Qu, E. Lee and T. Luo, ACS Energy Lett., 2020, 5(2), 437-456.

4 P. Wang, Environ. Sci.: Nano, 2018, 5, 1078-1089.

5 F. Zhao, Y. Guo, X. Zhou, W. Shi and G. Yu, Nat. Rev. Mater., 2020, 5, 388-401.

6 P. Tao, G. Ni, C. Song, W. Shang, J. Wu, J. Zhu, G. Chen and T. Deng, Nat. Energy, 2018, 3, 1031-1041.

7 S. Cao, P. Rathi, X. Wu, D. Ghim, Y. S. Jun and S. Singamaneni, Adv. Mater., 2020, 2000922.

8 Q. Zhao, C. Du, Y. Jia, J. Yuan, G. Song, X. Zhou, S. Sun, C. Zhou, L. Zhao and S. Yang, Chem. Eng. J., 2020, 387, 124131.

9 P. Zhang, Q. Liao, H. Yao, Y. Huang, H. Cheng and L. Qu, Energy Storage Mater., 2019, 18, 429-446.

10 J. Li, M. Du, G. Lv, L. Zhou, X. Li, L. Bertoluzzi, C. Liu, S. Zhu and J. Zhu, Adv. Mater., 2018, 1805159.

11 G. Li, W.-C. Law and K. C. Chan, Green Chem., 2018, 20, 3689-3695.

12 M. Gao, P. K. N. Connor and G. W. Ho, Energy Environ. Sci., 2016, 9, 3151-3160.

13 Y. Yuan, C. Dong, J. Gu, Q. Liu, J. Xu, C. Zhou, G. Song, W. Chen, L. Yao and D. Zhang, Adv. Mater., 2020, 1907975.

14 G. Wang, Y. Fu, A. Guo, T. Mei, J. Wang, J. Li and X. Wang, Chem. Mater., 2017, 29, 5629-5635.

15 Q. Zhang, X. Xiao, G. Wang, X. Ming, X. Liu, H. Wang, H. Yang, W. Xu and X. Wang, J. Mater. Chem. A, 2018, 6, 17212-17219.

16 Z. Guo, G. Wang, X. Ming, T. Mei, J. Wang, J. Li, J. Qian and X. Wang, ACS Appl. Mater. Interfaces, 2018, 10, 24583-24589.

17 F. Yu, Z. Chen, Z. Guo, M. S. Irshad, L. Yu, J. Qian, T. Mei and X. Wang, ACS Sustainable Chem. Eng., 2020, 8(18), 7139-7149.

18 S. Cheng, Z. Yu, Z. Lin, L. Li, Y. Li and Z. Mao, Chem. Eng. J., 2020, 401, 126108.

19 X. Meng, J. Yang, S. Ramakrishna, Y. Suna and Y. Dai, J. Mater. Chem. A, 2020, 8, 16570-16581.

20 X. Meng, J. Yang, S. Ramakrishna, Y. Sun and Y. Dai, ACS Sustainable Chem. Eng., 2020, 8, 4955-4965.

21 X. Dong, L. Cao, Y. Si, B. Ding and H. Deng, Adv. Mater., 2020, 1908269.

22 W. Zhang, X. Chen, G. Zhang, J. Li, Q. Ji, C. Hua, Z. J. Ren, H. Liu and J. Qu, J. Mater. Chem. A, 2020, 8, 12089-12096.

23 Q. Zhang, H. Yang, X. Xiao, H. Wang, L. Yan, Z. Shi, Y. Chen, W. Xu and X. Wang, J. Mater. Chem. A, 2019, 7, 14620-14628.

24 Q. Zhang, L. Ren, X. Xiao, Y. Chen, L. Xia, G. Zhao, H. Yang, X. Wang and W. Xu, Carbon, 2020, 156, 225-233.

25 Q. Zhang, R. Hu, Y. Chen, X. Xiao, G. Zhao, H. Yang, J. Li, W. Xu and X. Wang, Appl. Energy, 2020, 276, 115545.

26 K. Yang, T. Pan, I. Pinnau, Z. Shi and Y. Han, Nano Energy, 2020, 78, 105326.

27 L. Zong, M. Lia and C. Lia, Nano Energy, 2018, 50, 308-315. 
28 Z. Zheng, H. Li, X. Zhang, H. Jiang, X. Geng, S. Li, H. Tu, X. Cheng, P. Yang and Y. Wan, Nano Energy, 2020, 68, 104298.

29 L. Zhu, T. Ding, M. Gao, C. K. N. Peh and G. W. Ho, Adv. Energy Mater., 2019, 1900250.

30 Y. Zhang, S. K. Ravi and S. C. Tan, Nano Energy, 2019, 65, 104006.

31 G. Cheng, X. Wang, X. Liu, Y. He and B. V. Balakinc, Sol. Energy, 2019, 194, 415-430.

32 X. Li, X. Min, J. Li, N. Xu, P. Zhu, B. Zhu, S. Zhu and J. Zhu, Joule, 2018, 2, 1-8.

33 B. Gong, H. Yang, S. Wu, Y. Tian, X. Guo, C. Xu, W. Kuang, J. Yan, K. Cen, Z. Bo and K. (Ken) Ostrikov, Carbon, 2021, 171, 359-367.

34 G. Ni, G. Li, S. V. Boriskina, H. Li, W. Yang, T. Zhang and G. Chen, Nat. Energy, 2016, 1, 16126.
35 L. Cui, P. Zhang, Y. Xiao, Y. Liang, H. Liang, Z. Cheng and L. Qu, Adv. Mater., 2018, 30, 1706805.

36 F. Liu, L. Wang, R. Bradley, B. Zhao and W. Wu, Adv. Sustainable Syst., 2020, 1900122.

37 J. Ma, Y. Han, Y. Xu, T. Zhang, J. Zhang, D. Qi, D. Liu and W. Wang, J. Mater. Chem. A, 2020, 8, 21771-21779.

38 W. Li, Z. Li, K. Bertelsmann and D. E. Fan, Adv. Mater., 2019, 1900720.

39 Z. Guo, F. Yu, Z. Chen, Z. Shi, J. Wang and X. Wang, Sol. Energy Mater. Sol. C, 2020, 211, 11053.

40 F. L. Meng, M. Gao, T. Ding, G. Yilmaz, W. L. Ong and G. W. Ho, Adv. Funct. Mater., 2020, 2002867.

41 Y. Yuan, C. Dong, J. Gu, Q. Liu, J. Xu, C. Zhou, G. Song, W. Chen, L. Yao and D. Zhang, Adv. Mater., 2020, 1907975. 